Revista Destaques Acadêmicos, Lajeado, v. 9, n. 4, 2017. ISSN 2176-3070

DOI: http://dx.doi.org/10.22410/issn.2176-3070.v9i4a2017.1519

www.univates.br/revistas

\title{
AVALIAÇÃO DE PRODUTO NATURAL COMO INIBIDOR DE CORROSÃO PARA AÇO CARBONO EM MEIO ÁCIDO EM ENSAIOS DE TRAÇÃO
}

\author{
Carla C. Dias ${ }^{1}$, Karina Carla F. Batista ${ }^{1}$, Kátia Kelly B. Bandeira ${ }^{1}$, \\ Cícero V. Abreu², Maria de Lourdes Martins Magalhães², \\ Suleima Evelyn B. Pereira ${ }^{2}$
}

\begin{abstract}
Resumo: O elevado gasto relacionado a perdas de equipamentos e produtos industriais demonstra um interesse tecnológico na análise e minimização da degradação de materiais metálicos decorrente da corrosão química ou eletroquímica. $\mathrm{O}$ aço é o material mais empregado nos segmentos de bens de produção e por isso assume grande importância na sociedade. Composto por uma liga metálica, formada essencialmente por ferro e carbono, apresenta consideráveis propriedades mecânicas que podem ser verificadas através de ensaios mecânicos que reproduzem as condições de trabalho do material. A busca pelo desenvolvimento econômico, além da preocupação com os processos corrosivos tem fomentado a busca de métodos eficientes na redução da degradação metálica em ambientes altamente corrosivos, tais como o industrial e marinho. Nesse âmbito, diversos estudos têm sido realizados como, por exemplo, o uso de inibidores de corrosão. Além disso, a relevância da preservação ambiental tem motivado a investigação da toxicidade dos inibidores de corrosão descartados no meio ambiente. O objetivo do presente trabalho é avaliar o comportamento do aço carbono 1020 em solução ácida na ausência e presença de extrato da folha do cafeeiro como inibidor de corrosão frente a ensaios mecânicos de tração. Os resultados demonstraram uma minimização no processo corrosivo além da redução no decaimento das propriedades mecânicas nos ensaios de tração com o uso do inibidor, o que representa uma redução de custos pelas indústrias além de uma perspectiva sustentável.
\end{abstract}

Palavras-chave: Ensaios de tração. Corrosão. Inibidor natural. Aço carbono.

1 Universidade Estácio de Sá - Campus Praça XI.

2 Professor do Departamento de Engenharia Mecânica da Universidade Estácio de Sá - Campus Praça XI. 


\section{INTRODUÇÃO}

$\mathrm{O}$ aço carbono é uma liga de ferro-carbono (Fe-C) em uma faixa compreendida entre $0,008 \% \mathrm{~m} / \mathrm{m}$ até $2,0 \% \mathrm{~m} / \mathrm{m}$ de carbono (GERDAU, 2017) e apresenta consideráveis propriedades mecânicas que permitem utilizações em diversos setores através de meios de transporte, do processo energético além de equipamentos que envolvem a indústria petrolífera, entre outros (SILVA; MEI, 2010).

Um dos aços mais utilizados é o aço carbono SAE 1020, devido a sua baixa temperabilidade, significativa soldabilidade e forjabilidade, indicado para peças em geral para máquinas, veículos, dutos, entre outros (GERDAU, 2017).

Como constituinte do aço carbono, o ferro é responsável pela reação anódica (1) no processo corrosivo, ocorrendo simultaneamente com a reação catódica (2) em diferentes regiões da superfície metálica (GENTIL, 2003).

$$
\begin{aligned}
& \mathrm{Fe} \rightarrow \mathrm{Fe}^{2+}+2 \mathrm{e}^{-} \\
& 2 \mathrm{H}^{+}+2 \mathrm{e}^{-} \rightarrow \mathrm{H}_{2}
\end{aligned}
$$

Os custos referentes a degradação de materiais metálicos é significativo, o que leva a um relevante impacto econômico e ambiental que correspondem a $4,0 \%$ do Produto Interno Bruto PIB) (PORTAL FATOR BRASIL, 2016). Assim, há cada vez mais estudos sobre o tema. Uma das técnicas mais utilizadas no controle e prevenção contra a corrosão é a utilização de inibidores de corrosão, onde são adicionados a diversos meios industriais, tais como, sistemas de refrigeração, geração de vapor, decapagem ácida, produção interna de oleodutos, gasodutos e caldeiras em indústrias mecânicas, metalúrgicas, petrolíferas, entre outros (ADAMIAN, 2008).

Os inibidores de corrosão são substâncias que quando adicionadas ao meio corrosivo em pequenas concentrações, minimizam ou até mesmo impedem a reação do metal com o meio e dessa forma reduzem a taxa de corrosão do material devido a inibição das reações anódica e/ou catódica, minimizando a taxa de difusão dos reagentes para a superfície do metal (SINGH; GUPTA; GUPTA, 2015). Em operações de limpeza de dutos, por exemplo, são utilizadas soluções ácidas que necessitam da adição de inibidores para que haja uma minimização do processo corrosivo.

Embora demandem uma simples utilização, os inibidores convencionais, como por exemplo, compostos heterocíclicos sintéticos (RAJA; SETHURAMAN, 2008) apresentam, em sua maioria, componentes químicos que afetam de forma prejudicial o meio ambiente devido à alta toxicidade como por exemplo, o descarte em plataformas de produção offshore para os corpos hídricos em campos petrolíferos (SASTRI, 2011).

O uso de inibidores não agressivos tem sido alvo de pesquisas em termos de preservação ambiental. Esses inibidores utilizam produtos naturais 
e são chamados de inibidores verdes, são biodegradáveis e não contêm metais pesados ou outros compostos tóxicos (RANI; BASU, 2012).

Estudos envolvendo os inibidores verdes têm se mostrado eficientes apresentam resultados satisfatórios como: Rocha et al. (2012), Sá (2010), Acharya et al. (2013), Al-Fakih; Aziz; Sirat (2015), Alaneme; Olusegen; Adelowo (2016).

O uso de tecnologias limpas no processo produtivo possibilita que as empresas obtenham benefícios ambientais, devido à minimização na geração de resíduos e ao uso efetivo de insumos. Além disso, torna-se necessário avaliar as diversas estratégias em um cenário ambiental cada vez mais consciente.

Considerando a importância do tema, o objetivo do presente trabalho é avaliar a eficiência dos ensaios de tração no aço carbono 1020 sob um meio corrosivo na ausência e presença de extrato de café como inibidor natural de corrosão.

\section{METODOLOGIA}

\subsection{Preparação do inibidor por infusão aquosa}

A folha do cafeeiro contém substâncias antioxidantes, entre elas, em maior proporção, cafeína, ácido cafeico e o ácido clorogênico. Este último está na proporção de 7 a 10\% a mais que a cafeína (TRUGO, 1984).

Para a produção dos extratos, utilizou-se folhas de cafeeiro, como indica a Figura 1. Inicialmente, pesou-se 7,0000 g de folhas picadas do cafeeiro em balança analítica com precisão de 0,1 mg. Em seguida, adicionou-se $200 \mathrm{~mL}$ de água destilada e deionizada, submeteu-se a banho-maria a temperatura constante de $80{ }^{\circ} \mathrm{C}$, durante 15 minutos e filtrou-se a vácuo com papel de filtro quantitativo. $\mathrm{O}$ filtrado foi armazenado em recipiente de vidro âmbar e acondicionado em geladeira até a realização dos ensaios gravimétricos. O extrato foi mantido em geladeira até a realização dos ensaios gravimétricos. 
Figura 1 - Folhas picadas do cafeeiro para a produção do extrato

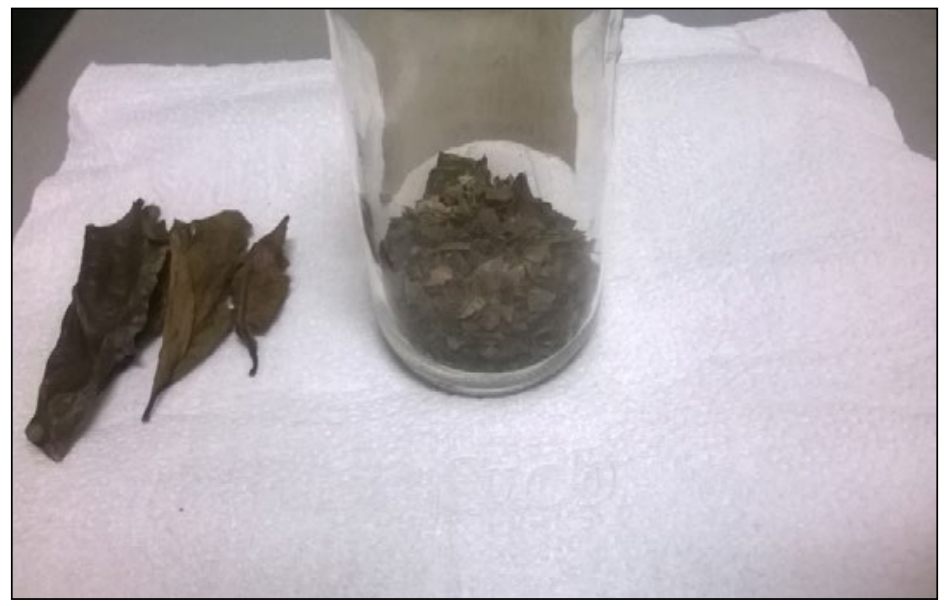

Fonte: Elaborado pelos autores.

\subsection{Produção dos corpos de prova}

Os corpos de prova $(\mathrm{CP})$ de tração foram fabricados com aço carbono 1020, de acordo com a norma ASTM 1E8/E8M-15 (2015). As dimensões básicas encontram-se na Figura 2. Antes dos ensaios corrosivos, os CPs foram polidos com lixas d'água, com granulometria de 100 a 600 mesh lavados com água deionizada, secos e mantidos em dessecador até a realização dos ensaios.

Figura 2 - Esquema do corpo de prova de tração

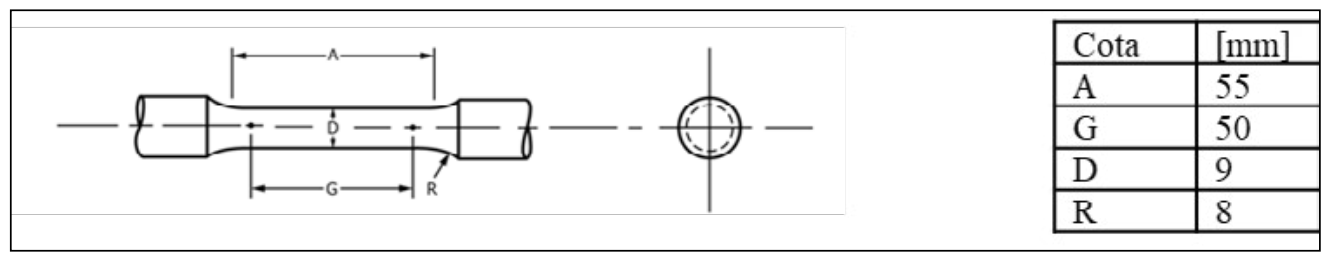

Fonte: Elaborado pelos autores.

\subsection{Ensaios gravimétricos - perda de massa por imersão total (IT)}

Os corpos de prova de aço carbono foram imersos em solução aquosa de ácido clorídrico $(\mathrm{HCl}) 1 \mathrm{~mol} \mathrm{~L}^{-1}$, na ausência e presença do inibidor, à temperatura de $25{ }^{\circ} \mathrm{C}$ durante 24 horas. Nos ensaios em presença do inibidor foram utilizados $12,5 \mathrm{~mL}$ do extrato com adição de $\mathrm{HCl}$ à $250 \mathrm{~mL}$, como representado na Figura 3. Os ensaios foram realizados em situ e em triplicata. Após os ensaios, os CPs foram lavados com água deionizada e secos com ar. 
Figura 3 - Ensaio de perda de massa do corpo de prova na presença do inibidor

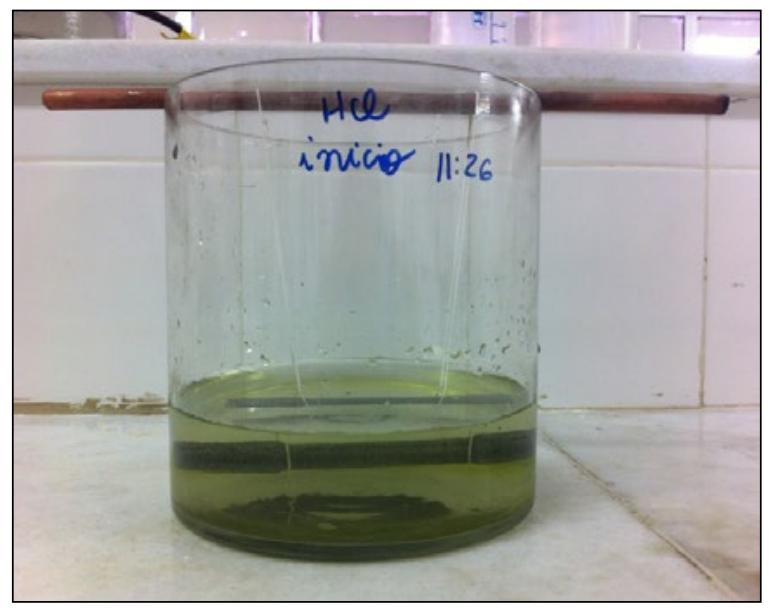

Fonte: Elaborado pelos autores.

A massa dos corpos de prova foi verificada antes e após a imersão em balança analítica, sendo empregada no cálculo da taxa de corrosão (), segundo a equação 1.

$T C(\mathrm{~mm} / \mathrm{ano})=\frac{\Delta m \times 87600}{A \times \rho \times t}$

Onde:

$\Delta \mathrm{m}=$ massa inicial do corpo de prova $(\mathrm{g})$ - massa final do corpo de prova $(\mathrm{g})$

$A=$ área do corpo de prova $\left(\mathrm{cm}^{2}\right)$

$\rho=$ densidade do aço $\left(\mathrm{g} \mathrm{cm}^{-3}\right)$

$t=$ tempo de imersão $(\mathrm{h})$

A eficiência de inibição (EI) foi calculada com base nos valores das taxas de corrosão dos ensaios na ausência e presença do inibidor, de acordo com a equação 2.

$$
I(\%)=\frac{T C_{0}-T C}{T C_{0}} \times 100
$$

Onde $T C_{0}$ e $T C$ são a taxa de corrosão na ausência e presença de inibidor, respectivamente.

\subsection{Ensaios de tração}

Os ensaios foram realizados na máquina de ensaios universal EMIC DL 10000, com capacidade de $100 \mathrm{kN}$ e velocidade de avanço de $5 \mathrm{~mm} \mathrm{~min}^{-1}$. Os CPs foram avaliados sem corrosão, na ausência e na presença do inibidor. Os 
ensaios foram realizados no Instituto Militar de Engenharia (IME). A Figura 4 apresenta um $\mathrm{CP}$ após a fixação à máquina no momento da avaliação.

Figura 4 - Ensaio de tração

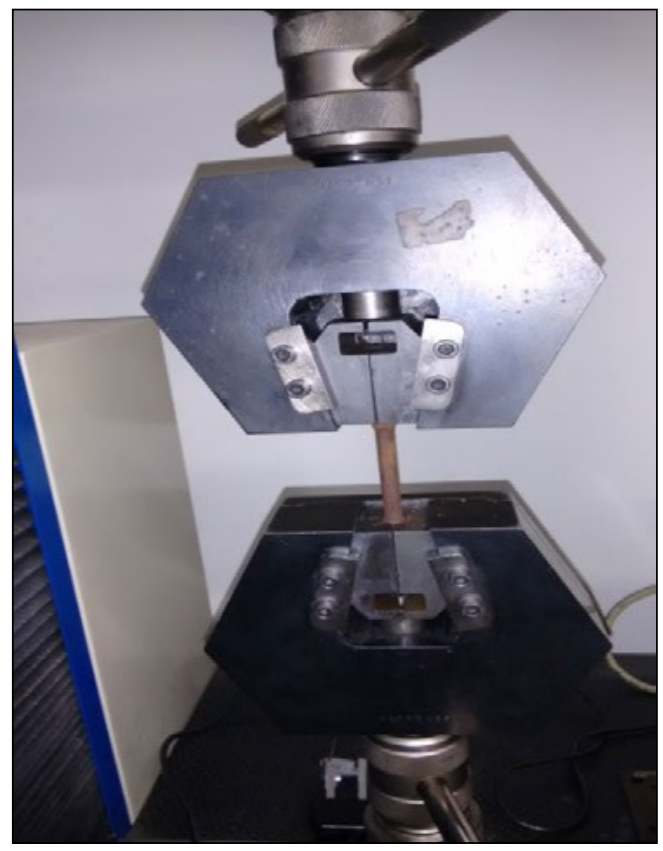

Fonte: Elaborado pelos autores.

\section{RESULTADOS E DISCUSSÃO}

\subsection{Ensaios gravimétricos - perda de massa em imersão total (IT)}

A Figura 5 apresenta o corpo de prova após a imersão em $\mathrm{HCl}$ sem inibidor por um período de 24 horas. É possível observar a presença de produtos de corrosão na superfície do aço, decorrente da ação do meio ácido agressivo. $\mathrm{O}$ aço carbono sofre corrosão generalizada em toda a superfície quando é imerso em $\mathrm{HCl} 1 \mathrm{~mol} \mathrm{~L}^{-1}$, apresentando rugosidade característica, o que indica que, em uma solução livre de extrato inibidor, a superfície apresenta-se altamente corroída (SÁ, 2010). 
Figura 5 - Corpo de prova após ensaios de imersão por 24 horas em meio ácido sem inibidor

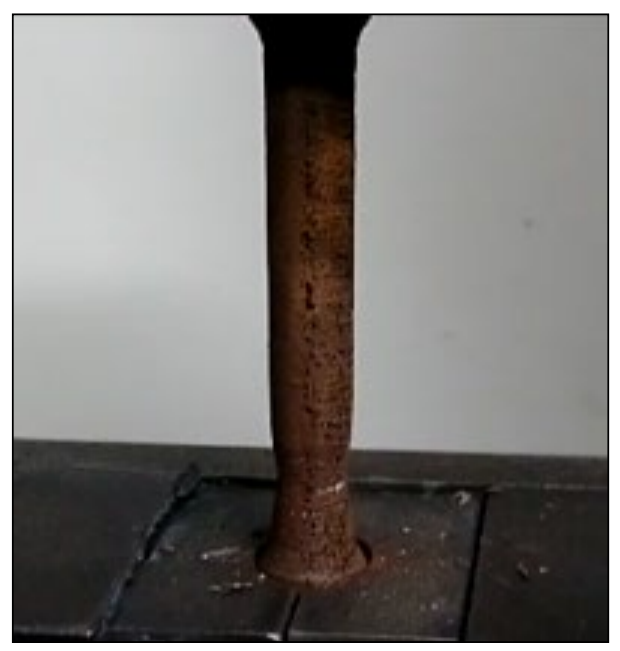

Fonte: Elaborado pelos autores

A Tabela 1 apresenta os resultados obtidos nos ensaios de perda de massa em IT dos corpos de prova do aço carbono 1020 em solução ácida, na ausência e presença do inibidor.

Tabela 1 - Resultados dos ensaios de IT do aço 1020 em solução de $\mathrm{HCl} 1 \mathrm{~mol} \mathrm{~L}^{-1}$ na ausência e presença de inibidor por 24 horas

\begin{tabular}{c|c|c|c}
\hline & \multicolumn{3}{|c}{ Aço carbono $1020 \mathrm{em} \mathrm{HCl} 1 \mathrm{~mol} \mathrm{~L}^{-1}$} \\
\hline $\mathbf{C P}$ & $\Delta \mathrm{m}(\mathrm{g})$ & T.C. $\left.\mathbf{( m m ~} \mathbf{~ a n o}^{-1}\right)$ & E.I. (\%) \\
\hline Sem inibidor & 1,0505 & 5,0021 & - \\
\hline Com inibidor & 0,0831 & 0,3244 & 89,43 \\
\hline
\end{tabular}

Fonte: Elaborado pelos autores

Os resultaram dos ensaios indicaram que os valores das taxas de corrosão no ensaio do $\mathrm{CP}$ sem inibidor, foram significativos, o que era esperado.

A variação observada na Tabela 1 entre os dois meios, provavelmente reflete a formação de um filme protetor do inibidor sobre a superfície metálica nesse período de tempo, o que não ocorreu quando o aço foi exposto ao meio de $\mathrm{HCl} 1 \mathrm{~mol} \mathrm{~L}^{-1}$. Resultados semelhantes foram obtidos por Yaro et al. (2013).

Assim, as moléculas das substâncias antioxidantes do filme produzido pelo extrato das folhas do cafeeiro que atuam de forma inibitória, possivelmente foram adsorvidas na superfície do substrato de aço 1020 formando uma camada 
protetora sobre o metal, o que já foi observado a partir de outros inibidores naturais (ROCHA et al., 2012).

A adsorção ocorre no contato entre a superfície metálica e uma solução de determinada composição do inibidor. Decorrido um intervalo de tempo, ocorre o equilíbrio entre as moléculas do inibidor e a superfície metálica. A relação entre a quantidade adsorvida, $\mathrm{q}$, e a concentração do inibidor, $\mathrm{C}$, em uma determinada temperatura, $\mathrm{T}$, é chamada de isoterma de adsorção na referida temperatura (SUZUKI, 1990).

Quando o aço é imerso no meio, inicialmente os íons cloreto são adsorvidos na superfície metálica, reduzindo o grau de hidratação e criando um excesso de cargas negativas na solução, favorecendo a adsorção de cátions. As moléculas dos inibidores carregados positivamente são adsorvidas na superfície metálica através dos íons cloreto que formam pontes interligando os átomos do metal e os cátions orgânicos (TANG, 2006).

\subsection{Ensaios de tração}

Os resultados dos ensaios de tração encontram-se na Tabela 2, onde foram registrados o limite de escoamento, limite de resistência, alongamento percentual e redução de área.

Tabela 2 - Ensaios de tração do aço carbono sem corrosão e em meio corrosivo na ausência e presença de inibidor

\begin{tabular}{c|c|c|c|c|c|c|c|c}
\hline $\begin{array}{c}\text { CP } \\
\text { Ensaio de } \\
\text { Tração }\end{array}$ & $\begin{array}{c}\text { Limite de } \\
\text { Escoamen- } \\
\text { to (Mpa) }\end{array}$ & $\%$ & $\begin{array}{c}\text { Limite de } \\
\text { Resistên- } \\
\text { cia (Mpa) }\end{array}$ & $\%$ & $\begin{array}{c}\text { Alongamen- } \\
\text { to (\%) }\end{array}$ & $\%$ & $\begin{array}{c}\text { Redu- } \\
\text { ção de } \\
\text { Área } \\
\text { (\%) }\end{array}$ & $\%$ \\
\hline $\begin{array}{c}\text { Ausência } \\
\text { de corrosão }\end{array}$ & 119,50 & 0 & 345,00 & 0 & 47,00 & 0 & 76,11 & 0 \\
\hline $\begin{array}{c}\text { Ausência } \\
\text { de inibidor }\end{array}$ & 85,19 & 28,71 & 288,55 & 16,36 & 28,20 & 40,00 & 55,06 & 27,56 \\
\hline $\begin{array}{c}\text { Presença de } \\
\text { inibidor }\end{array}$ & 108,80 & 8,95 & 341,24 & 1,09 & 32,00 & 31,91 & 75,00 & 1,46 \\
\hline
\end{tabular}

Fonte: Elaborado pelos autores

Assim, pode-se observar que os corpos de prova que sofreram ataque corrosivo na presença de inibidor apresentaram resultados intermediários de limites de escoamento e resistência entre os CPs com ausência de corrosão e com ataque corrosivo na ausência do inibidor, o que demonstra a eficiência do inibidor frente ao ensaio mecânico de tração.

As fraturas nas superfícies de fratura apresentaram características macroscópicas de falha comuns em materiais dúcteis, do tipo taça e cone (CHIAVERINI, 1999, p. 56) como mostra a Figura 6. 
Figura 6 - Corpos de prova após fratura no ensaio de tração. (a) sem corrosão; (b) com corrosão; (c) com corrosão atenuada por inibidor.

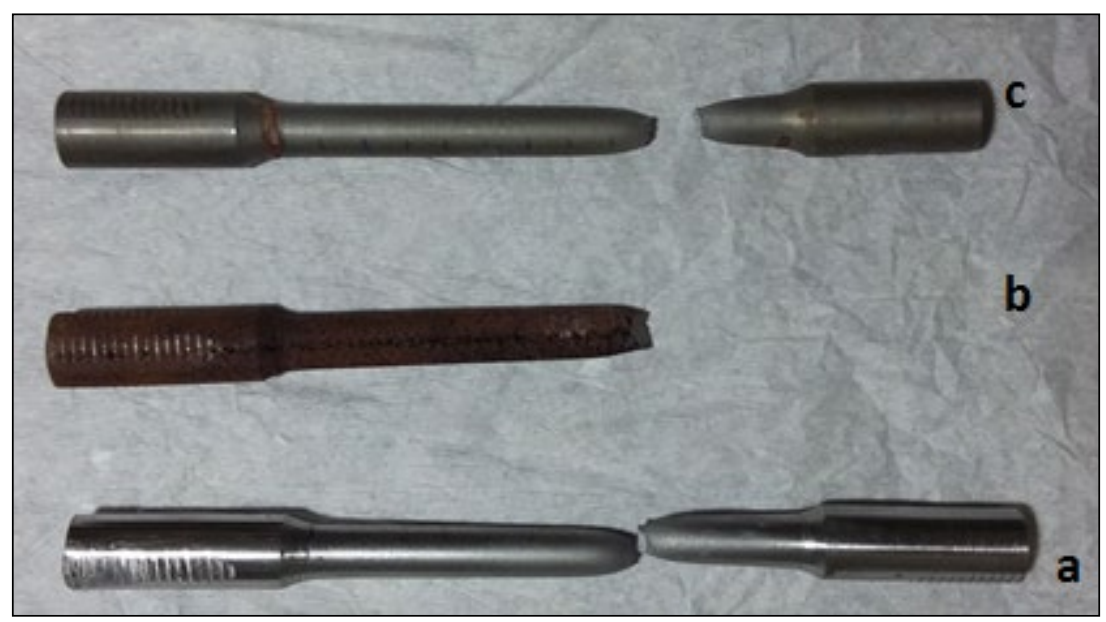

Fonte: Elaborado pelos autores.

O decréscimo no alongamento percentual e na redução percentual de área, principalmente no $\mathrm{CP}$ exposto ao ataque corrosivo na ausência do inibidor, demonstra uma tendência à fragilização do aço pela corrosão.

\section{CONCLUSÃO}

Com base nos resultados dos ensaios de perda de massa, verifica-se que o extrato da folha do cafeeiro apresenta um comportamento satisfatório em relação à inibição do processo corrosivo do aço carbono 1020 em solução ácida, nas condições estudadas.

A inclusão de inibidores associados a produtos ácidos mostrou-se eficaz na atenuação da redução das propriedades mecânicas do aço 1020. Como exemplo, as operações de limpeza de dutos, para as quais soluções ácidas são requeridas, tornar-se-iam menos agressivas ao material.

A identificação dos processos de fratura sob corrosão aponta a tendência à fragilização do material, o que também podem ser restringido com a aplicação de inibidores.

Falhas de materiais metálicos expostos a meios corrosivos e tensão, principalmente tensões cíclicas, devem ser constantemente estudadas já que englobam a maioria das causas de fraturas em componentes estruturais.

A demanda por um desenvolvimento sustentável requer o uso de tecnologias que possibilitem melhor utilização dos recursos produtivos e um eficiente controle ambiental. 


\section{REFERÊNCIAS}

ACHARYA, M.; CHOUHAN, J. S; DIXIT, A; GUPTA, K. Green inhibitor for prevention of metal and alloys corrosion: An overview. Chemistry and Materials Research, v. 3(6), p.16-24, 2013.

ADAMIAN, R. Novos materiais. Tecnologia e aspectos econômicos. Rio de Janeiro: COPPE/UFRJ, 2008.

AL-FAKIH, A. M.; AZIZ M.; SIRAT, H. M. Turmeric and ginger as green inhibitors of mild steel corrosion in acidic medium. Journal of Materials and Environmental Science, v. 6(5), p. 1480-7, 2015.

ALANEME, K. K.; OLUSEGEN, S. J.; ADELOWO, O.T. Corrosion inhibition and adsorption mechanism studies of Hunteria umbellata seed husk extracts on mild steel immersed in acidic solutions. Alexandria Engineering Journal, v. 55, p. 673-681, 2016.

AMERICAN SOCIETY FOR TESTING AND MATERIALS. ASTM E8/E8M - 15a: Standard Test Methods for Tension Testing of Metallic Materials, Philadelphia, EUA, 2015.

ASSOCIAÇÃO BRASILEIRA DE NORMAS TÉCNICAS . ABNT NBR ISSO 6892:13:

Materiais metálicos - Ensaio de Tração. Parte 1: Método de ensaio à temperatura ambiente, 2013.

CHIAVERINI,V. Aços carbono e Aços Liga: Características Gerais, Tratamentos Térmicos, Principais Tipos. Publicação da Associação Brasileira de Metais. São Paulo, SP. 1999. 255 p.

GENTIL, V. Corrosão - 4a Edição, Rio de Janeiro: LTC, 2003.

GERDAU S.A. Disponível em: < https:/ / www.gerdau.com/br/pt/ProductSearch?k=a\%C3\%A7o\%201020\#k=a\%C3\%A7o $1020>$. Acesso em 12/09/2017.

PORTAL FATOR BRASIL. Disponível em: http:/ /www.revistafatorbrasil.com.br/ ver_noticia.php?not=334281, 2016. Acesso em 14/01/2018.

RAJA P. B.; SETHURAMAN, M. G. Materials Letters, 62, p. 113-116, 2008.

RANI, B. E. A.; BASU, B. B. J. International Journal of Corrosion, 2012, Artigo ID 380217, 15 páginas, 2012.

ROCHA, J. C.; PONCIANO, J. A.C.G.; D'ELIA, E.; CRUZ, A. P. G. ; CABRAL, L. M. ; TORRES, A.G.; MONTEIRO, M. V. Grape Pomace Extracts as Green Corrosion Inhibitors for Carbon Steel in Hydrochloric Acid Solutions. International Journal of Electrochemical Science, 7, p. 11941- 11956, 2012. 
SÁ, C. F. Extratos de mate verde e carqueja como inibidores de corrosão do açocarbono 1020 em meio de ácido clorídrico. Dissertação-Universidade Federal do Rio de Janeiro - UFRJ, Programa de Pós-Graduação em Química - IQ, 2010.

SASTRI, V. S. Green Corrosion Inhibitors: Theory and Practice, First Edition. 2011 John Wiley \& Sons, Inc. Published 2011 by John Wiley \& Sons, Inc.

SILVA, A. L. V. C.; MEI, P. R. Aços e Ligas Especiais, $3^{\text {a }}$ ed. revista e ampliada, editora Edgard Blucher, 2010.

SINGH, M. R.; GUPTA, P.; GUPTA, K. The Litchi (Litchi Chinensis) peels extract as a potential green inhibitor in prevention of corrosion of mild steel in $0.5 \mathrm{M} \mathrm{H}_{2} \mathrm{SO}_{4}$ Solution, Arabian Journal of Chemistry, v. 5, p. 467-474, 2015.

SUZUKI, M. Adsorption Engineering, Tokio: Kodansha LTD e Amsterdam: Elsevier Science Publishers B. V., 1990.

TANG, L.; LI, X.; LI, L.; MU, G.; LIU, G. The effect of 1-(2-pyridylazo)-2-naphthol on the corrosion of cold rolled steel in acid media: Part 2: Inhibitive action in $0.5 \mathrm{M}$ sulfuric acid. Materials Chemistry and Physics, v. 97, n 2-3, p. 301-307, 2006.

YARO, A. S.; KHADOM, A. A.; WAEL, R. K. Apricot juice as green corrosion inhibitor of mild steel in phosphoric acid. Alexandria Engineering Journal, v.52, n. 1, p. 129135, 2013. 